\title{
Understanding and managing global change in small islands
}

\author{
John E. Hay · Donald L. Forbes $\cdot$ Nobuo Mimura
}

Received: 8 May 2013/Accepted: 16 May 2013/Published online: 30 May 2013

(C) Springer Japan 2013

Keywords Small islands · Vulnerability · Risk ·

Adaptation · Resilience

$\begin{array}{ll}\text { Abbreviations } \\ \text { ENSO } & \text { El Niño-Southern Oscillation } \\ \text { IPCC } & \text { Intergovernmental Panel on Climate Change } \\ \text { LOICZ } & \text { Land-Ocean Interactions in the Coastal Zone } \\ \text { SIDS } & \text { Small island developing states } \\ \text { YICZR } & \text { Yantai Institute of Coastal Zone Research }\end{array}$

\section{Introduction}

Climate variability and change, associated changes in sea level, ocean acidification and surface warming, extreme events such as tropical cyclones and tsunamis, and the quality and quantity of freshwater resources are among the major environmental issues related to the sustainable development of small islands, including small island developing states (SIDS). In addition to natural change and hazards, principal sources of stress on small islands include changing social, demographic, economic, cultural, and governance conditions and maladaptive local development initiatives. As global pressures increase, including those

\author{
J. E. Hay $(\bowtie) \cdot$ N. Mimura \\ Institute for Global Change Adaptation Science (ICAS), \\ Ibaraki University, Environment Research Laboratory Building, \\ 2-1-1 Bunkyo, Mito, Ibaraki 310-8512, Japan \\ e-mail: johnhay@ihug.co.nz \\ D. L. Forbes \\ Department of Geography, Memorial University \\ of Newfoundland, St. John's, NL A1B 3X9, Canada
}

related to climate change, the ability to cope with the adverse consequences of complex change may be compromised increasingly by limits to adaptive capacity, unsustainable development practices, institutional barriers, and other governance challenges. Island communities are social-ecological systems and their resilience in the face of uncertain futures (environmental, economic, and others) and surprises (extreme events) is a key element of sustainability (Kates et al. 2000; Adger 2006; Adger et al. 2005).

Small island developing states and small islands within larger states are physical, ecological, and social entities with distinctive attributes related to their insularity, remoteness, size, geographic setting, climate, culture, governance, and economy (e.g. Pelling and Uitto 2001; Mimura et al. 2007; Hay 2013; Forbes et al. 2013). Yet despite the sense of separation that attends the experience of small islands, global change in a variety of forms impinges directly or indirectly on the environment and sustainability of these island communities. As a group, they pose some of the most striking challenges to sustainability science. Low-lying island states, such as the Maldives and Tuvalu, face pressing concerns about the limits to habitability under accelerated sea-level rise, the result of a warming global climate. Ocean warming and acidification pose threats to the conservation of reef corals and the stability and resilience of coral reefs under rising sea level (IPCC 2007). Together with concerns about freshwater resources, these environmental threats exacerbate challenges related to small size and remoteness, demographic pressures, small markets and limited economic opportunities, high per-capita infrastructure costs, reliance on external finance, limited technical capacity (including capacity for disaster response, recovery, and risk reduction), and cultural transformation through processes such as 
labour exports, growing international exposure, and internet access.

The small populations and resource constraints of many small island states can limit the technical capacity of island institutions to deal with these challenges under conditions in which past experience (traditional knowledge) may be a poor guide to the future. Solutions may be found by way of technical (e.g. hard or soft engineering), institutional, political or other approaches. Furthermore, there is a need to understand the multiple sources of hazards and threats, some of which originate with global climate change, while others may be due to maladaptive development at community and island scales (cited by several papers in this Special Issue). If major reductions in greenhouse gas emissions are achieved, but local maladaptation continues, it is quite possible that negative climate-change impacts will still occur. Thus small islands may be both victims and agents of inadequate responses to climate change. It is therefore important to reduce vulnerability, to seek and implement affordable adaptation strategies, to support joint efforts at regional and international levels, and to build resilience by incorporating adaptation needs and options into the awareness, decision making, planning and actions of those living on small islands (Jerneck et al. 2011).

An international conference on 'Coastal Systems, Global Change and Sustainability', convened in Yantai, China, in September 2011, served as the catalyst for this Special Issue of Sustainability Science. The conference, organised by Land-Ocean Interactions in the Coastal Zone (LOICZ) and the Yantai Institute of Coastal Zone Research (YICZR), was hosted by YICZR and the Chinese Academy of Sciences, with support from the Centre for Materials and Coastal Research, Helmholtz-Zentrum, Geesthacht, Germany. The aim of the conference was to bring together the international research community working on land-ocean issues, to showcase the breadth and scope of ongoing research, to help build a community-of-interest in this highly interdisciplinary field, and to inspire new research, theory, and applied science. The organisers gave priority to an integrated approach by drawing on a diversity of experiences and disciplinary perspectives worldwide in order to generate new levels of understanding and improve policy, decision-making, and planning practice.

The conference included a special session on Islands at Risk: Small Island Developing States. Many of the papers in this Special Issue were presented initially in the small islands session, which focussed on the constraints, challenges, and potential strategies for coping with existing and projected coastal hazards in the context of climate change and extreme events. Many consequences of changes in climate will first be felt in extreme events, which therefore require careful attention along with the potential for climate 'surprises'.
Of the 11 papers in this Special Issue, 6 had their origins in the 2011 Yantai conference. The others are included because of their relevance to the theme of the conference and their contribution to a broader discussion of small islands issues. While the majority of the papers arise from research undertaken in the Pacific Islands region, in particular Kiribati and Tuvalu, other papers report research findings for the Bahamas and Trinidad and Tobago. Another paper draws examples from small islands in three major oceans with robust local sea-level projections for 18 small island sites around the world. One paper discusses environmental management in coastal and small-island communities in both Canada and the Caribbean. Still others present findings of research with global relevance to all SIDS and other small islands. A similar diversity is seen in the authorship of the papers, with representation both from SIDS and from the broader global research community.

Figure 1 shows that the papers cover three key aspects of understanding and managing global change in small islands:

- learning from the past and anticipating the future;

- understanding and assessing hazards, exposure, risk, vulnerability, resilience, and sustainability; and

- managing current and future change.

Both exposure and vulnerability of specific small islands, and of SIDS generally, receive considerable attention, as do adaptation and other approaches to managing environmental and related changes. Approaches, methods and tools, such as ecosystem-based adaptation to climate change, communication and education strategies, and experience with an international community of practice, representing components of sustainability science, are considered in various papers.

\section{Overview of papers in this Special Issue}

Following is a brief synopsis of the papers in this Special Issue. The aim is not to summarize the content of each paper but to demonstrate that individually and collectively the papers make an important contribution to our understanding of sustainability challenges and strategies for building resilience in small island communities and states.

Understanding and managing global change pressures and processes in SIDS and other small islands

The paper by Hay (Small islands: coastal systems, global change and sustainability) is a significant expansion on the invited keynote presentation in the small islands session of the 2011 conference. The paper highlights important points made in two recent studies. The first is that, while SIDS 


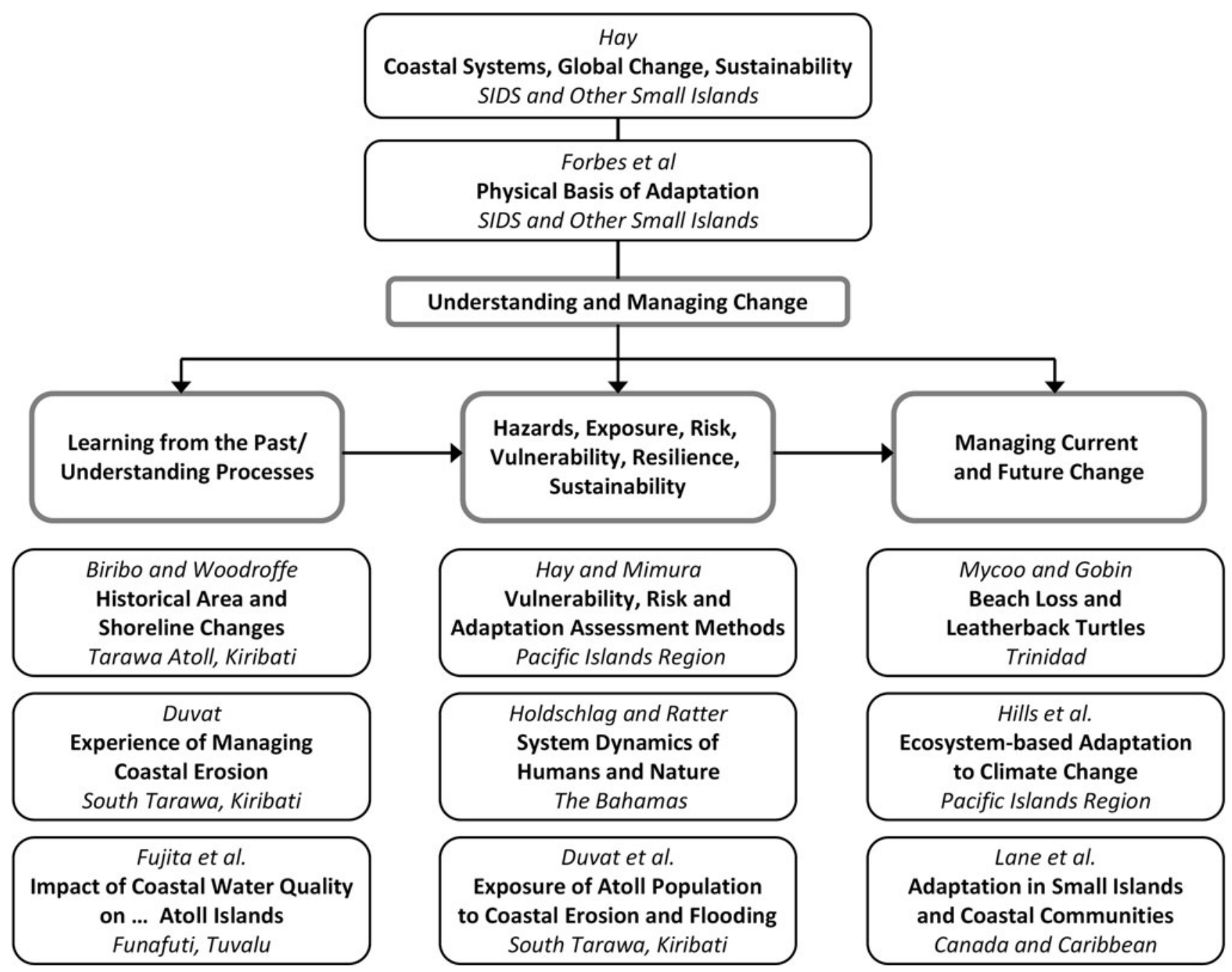

Fig. 1 Titles, authors and thematic focus of papers in this Special Issue. The papers are organised under three themes related to understanding and managing global change in small islands

and other small islands have long been represented as sites of vulnerability, communities on many such islands have in fact survived for millennia. Only over the past few centuries and, more particularly, in recent decades, have the processes of colonialism, development and globalisation caused lower resilience and greater exposure, thereby increasing vulnerability. Secondly, globalisation is nothing new for many SIDS and other small islands. Generally they have had a long history of being reshaped by shifts in international economic and political relations, and the spread of technological innovation. It is argued that the more recent global pressures on SIDS and other small islands are characterised by time-space compression-they seem to be occurring more rapidly and with wider reach.

In order to fully understand and respond to these and other findings on how global change has, does and will affect SIDS and other small islands, the paper clarifies the concepts of exposure, risk, vulnerability, resilience and sustainability and suggests a suite of management interventions that will help reduce the vulnerability and enhance the resilience of small islands to global and other changes. Thus the paper covers the three key aspects of understanding and managing global change in small islands (Fig. 1), and provides the context for the other papers in this Special Issue.

The paper by Forbes and co-authors (Physical basis of adaptation on tropical small islands) considers the global and island-specific physical context in which island communities are exposed to the impacts of climate change and natural hazards. While recognizing that physical exposure is only one component of vulnerability, the paper highlights the importance of the physical setting in defining hazard risk and determining suitable and feasible interventions. The paper proposes a physical classification of island types whereby the relative importance of various climate-change effects and coastal hazards can be assessed. 
The authors show how the applicability and importance of representative adaptation actions vary to some extent with island type. This paper also makes an important contribution to global and local analysis of sea-level rise as applied to small tropical and sub-tropical islands. It points to the role of global gravitational effects in relation to the location of meltwater sources, while demonstrating the need for realistic estimates of local vertical crustal motion (uplift or subsidence) as input to robust projections of relative sealevel rise. The importance of these input data, which are completely lacking for many islands, highlights a major knowledge gap for local sea-level projections and adaptation planning. Despite the utility of an island classification for understanding the nature of exposure and potential response for various island types, the paper emphasizes the need for place-based analysis in assessing potential impacts and developing appropriate climate-change adaptation and disaster risk-reduction policies. These themes are taken up in some of the following papers.

Theme 1: learning from the past: understanding coastal processes

Biribo and Woodroffe (Historical area and shoreline change of reef islands around Tarawa Atoll, Kiribati) note that general perceptions on the response of reef-island shorelines to global change range from increased erosion (resulting in a reduction in island size) to more accretion (leading to an increase in land area). Using a temporal change approach, they document contrasting influences on reef-island shorelines between North and South Tarawa over the past 30 years. Changes in North Tarawa are largely influenced by natural factors, while those in South Tarawa are affected predominantly by human interventions. Both are affected by global factors, such as rising mean sea level over the period of study, and by seasonal variability associated with the El Niño-Southern Oscillation (ENSO). The authors conclude that Tarawa Atoll has increased in size, gaining about 450 ha, largely as a result of development-related reclamation in South Tarawa. Biribo and Woodroffe build on these insights to suggest technical and governance strategies that will enhance the resilience in Tarawa. These include acknowledging coastal processes and ENSO variability in the designs of coastal structures, prohibiting beach mining, and finding alternative construction materials.

Duvat (Facing coastal erosion in atoll countries) also used South Tarawa as a case study to gain further insight into how natural processes are influenced by coastal development and protection measures. Even within South Tarawa there are considerable differences in land use, with an urban to rural continuum observed from west to east. This is coincident with a coastal protection gradient, with structures (mostly seawalls) being widespread on urban islands, but more localised or absent in rural settings. On urban islands there is extensive mining of sand and coral blocks, contributing significantly to sand loss and sediment transport disruption, creating irreversible disturbance to coastal processes and complete destabilization of the shoreline in some areas. The situation calls for a coherent plan that addresses the current inadequacy of environmental regulations and enforcement. This has led to an uncontrolled boom in private coastal development, including reclamation projects and coastal defences. The author also suggests the need to relocate threatened assets at the scale of the entire atoll, given that development pressures are expected to increase rapidly on North Tarawa reef islands.

Fujita and co-authors (Anthropogenic impacts on coastal water quality threatening the formation and maintenance of atoll islands) describe another pressure on the formation and maintenance of atoll islands, namely anthropogenic pollution of seawater over the reef flat affecting the productivity of calcifying organisms, such as coral, coralline algae, molluscs and large benthic foraminifera. These supply much of the sediment forming reef islands. They compared the current water quality of the densely populated lagoonal coasts of Fongafale, Funafuti Atoll, Tuvalu, with that of less populated and largely undeveloped parts of the island. Sample analyses revealed that coastal sediments along the urbanized coast exhibit significantly higher microbial biomass, different microbial community structure, and lower microbial diversity compared to the coastal sediments in less developed areas. This highlights the need for improved practices, including more effective management of domestic wastewater as a key strategy to maintain island health and stability.

Theme 2: hazards, exposure, risk, vulnerability, resilience and sustainability

Each of the preceding papers has highlighted the importance of understanding the processes by which the coastal systems of small island states respond to the pressures associated with global change. Assessments of hazards, exposure, risk, vulnerability and resilience are a critical part of managing the consequences of global change and ensuring the sustainability of small islands. Pacific Island countries have shown strong leadership in characterising the challenges of climate change, both nationally and for the region as a whole, and in identifying the most appropriate responses.

Hay and Mimura (Vulnerability, risk and adaptation assessment methods in the Pacific Islands region: past approaches, and considerations for the future) review the approaches, methods, and tools that been applied in 
vulnerability, risk and adaptation assessments in the Pacific Islands region. Numerous strategies are required because no one approach will address all needs and accommodate all capacities. But several successful approaches, methods, and tools can be identified. These principles are used to guide the development of a proposed higher-level framework for vulnerability, risk and adaptation assessments. This accommodates the various approaches, methods and tools commonly used with success in the Pacific, and suggests how such assessments might be undertaken more effectively in the future.

Holdschlag and Ratter (Multiscale system dynamics of humans and nature in the Bahamas: perturbation, panarchy and resilience) note that the dynamic interactions between social systems (integrated by governance and communication) and biophysical systems (connected by material and energy flows) present a major and ongoing challenge. They show that the resilience of island society is important in determining whether social-ecological systems develop sustainably, because social resilience is strongly influenced by social memory, learning and communication. For this reason, governance structures need to be flexible and adaptive to new and changing external pressures in order to generate the social capacity to deal with change. Resilience can be influenced by changes in organizational control processes, including information processing, as well as by functional diversity and social resourcefulness. It is essential to consider the local context, including social dynamics, varying path dependencies, and unpredictable changes in trajectory. The authors show that in the social sphere of the Bahamas, diverse and uncertain knowledge systems and underlying mental models of risk and environment acquired at different scales are key variables of change. This also applies to the processes of communication and education. Combining the various multilevel knowledge systems remains a major challenge for small island resilience and sustainability.

Duvat and co-authors (Exposure of atoll population to coastal erosion and flooding: a South Tarawa assessment, Kiribati) investigate the exposure of an atoll population to coastal erosion and flooding. They combine two sets of data, the first relating to shoreline changes and island elevation, and the second to population growth and associated land-use changes and housing development. Their results highlight the direct and indirect factors that contribute to a rapid increase in population exposure. Direct factors include population growth and low topographic elevation, while indirect factors include recent changes in land use and environmental degradation. Consistent with the notion of time-space compression discussed earlier in this paper, their findings also emphasize the rapidity of the changes, such as shoreline modification, environmental degradation, and the increased exposure of buildings.
Theme 3: managing current and future change

Mycoo and Gobin (Climate variability and climate-change adaptation in small coastal communities: leatherback turtles and beach loss) investigate the impacts of natural beach dynamics and projected climate change on small coastal communities where leatherback turtle nesting is a tourist attraction and economic anchor. They emphasize the natural variability of the beaches, which is important to recognise in the context of an endangered species dependent on beach ecosystems. Policymakers may be more concerned with the economic impacts of species decline and beach loss on coastal communities. Mycoo and Gobin explore the potential for convergence of science and policy through a case study at Grande Riviere, on the northeast coast of Trinidad. This site has the highest density of nesting leatherback turtles in the world, with 3,000 or more nesting on an $800 \mathrm{~m}$ length of beach. Although economic activity associated with turtle watching has not declined to date, Mycoo and Gobin suggest that such changes are possible if climate change and sea-level rise lead to alteration of beach habitat. They find that while community awareness of sea-level rise is relatively high, knowledge and awareness of climate change in general is low.

Hills and co-authors (A social and ecological imperative for ecosystem-based adaptation to climate change in Pacific islands) define ecosystem-based adaptation (EbA) approaches as the use of biodiversity and ecosystem services in an overall strategy for adaptation to adverse effects of climate change. They argue that $\mathrm{EbA}$ is an appropriate policy response to the range and sometimes severe impacts of climate change on Pacific island ecosystems. However they highlight a current divergence between the conceptual rationale for EbA and its application in practice. There are two dominant approaches to the application of EbA. Targeted actions (based on the appraisal of various adaptation options and their relative capacity to reduce societal vulnerability) will generally have more sophisticated data and analytical requirements than general approaches (based on the expected delivery of a wide range of ecosystem services, including those likely to reduce societal vulnerability). The latter are more appropriate in situations where the emphasis is on increasing resilience but there is high uncertainty about the local climate future, limited analytical capacity and/or limited resources for design, implementation and/or maintenance. The authors show that a number of characteristics make adaptation approaches utilising the benefits of ecosystems a compelling and viable alternative to other adaptation approaches. But without improved guidance for early-stage planning that allows practical 'whole-of-system' comparisons between EbA and non-EbA solutions, there has been little full integration of the former in national adaptation programs. A broad lack of 
awareness of the benefits of EbA is a challenge to its use in a region where 'bottom-up' approaches to prioritisation play an important role in policy and decision-making.

Lane and co-authors (The gathering storm: managing adaptation to environmental change in coastal communities and small islands) argue that small-island communities are inherently coastal communities, sharing many of the attributes and challenges faced by cities, towns and villages situated on the shores of larger islands and continents. SIDS and small islands in larger states are part of a distinctive set of stakeholders threatened, not only by climate change, but also by shifting social, economic and cultural conditions. The authors describe an international community-university research alliance (C-Change) whose goal is to assist participating coastal communities in Canada and the Caribbean to share experiences and tools that aid adaptation to such changes. Within this alliance, C-Change researchers have been working with eight partner communities to identify threats, vulnerabilities and risks, to improve understanding of the ramifications of climate change to local conditions and local assets, and to increase capacity for planning for adaptation to their changing world. They describe educational initiatives including the development of new interdisciplinary curricula at primary, secondary and postsecondary levels, as well as efforts to bolster public awareness. Information exchange and integration across all C-Change communities in Canada and the Caribbean is seen to be critical to improving effective uptake and expanding adaptive capacity. This is being addressed through the development of a community of practice involving planning staff and other professionals and stakeholders from participating C-Change communities.

\section{Sustainable development in small islands}

This Special Issue contributes to our wider understanding of global change and its implications for sustainable development on small islands. Overall, it shows that change, including that resulting from global processes, is not a new experience for most island communities. What is new is the time-space compression of the change processes, such that now the coping and adaptive capacities of the coupled human-environment systems of SIDS and other islands are severely stressed (Adger 2006; Adger et al. 2005). As global pressures, including those related to climate change, increase, the ability to cope with adverse consequences will depend on a move toward more sustainable development practices, combined with efforts to close knowledge gaps and communication barriers that compromise the quality of impact projections and adaptation policy.

Many of the papers in this Special Issue address core questions in sustainability science (Kates et al. 2000;
Turner 2010; Jerneck et al. 2011). What determines the vulnerability or resilience of coupled social-ecological systems on small islands? How can the key sustainability challenges be framed for specific island settings? How can knowledge be acquired, communicated, and structured to promote proactive adaptation actions to enhance safety and well-being in island communities? How can adaptive capacity and institutional flexibility be enhanced to cope with the interlaced pressures of global change in small island developing states? These questions have resonance globally, well beyond the reefs and shorelines of small islands, and there are no simple answers. Working toward solutions requires transdisciplinary and integrative approaches to systematic understanding, goal setting, strategy development, and implementation (Jerneck et al. 2011). The papers in this Special Issue provide some of the pieces to build the capacity to answer and act on these questions in small island communities around the world.

\section{References}

Adger WN (2006) Vulnerability. Global Environ Change 16:268-281 Adger WN, Hughes TP, Folke C, Carpenter SR, Rockström J (2005) Socialecological resilience to coastal disasters. Science 309:1036-1039

Forbes DL, James TS, Sutherland M, Nichols SE (2013) Physical basis of coastal adaptation on tropical small islands. Sustain Sci (this volume). doi: 10.1007/s11625-013-0218-4

Hay JE (2013) Small island developing states: coastal systems, global change and sustainability. Sustain Sci (this volume). doi: 10.1007/s11625-013-0214-8

IPCC (2007) Summary for policymakers. In: Parry ML, Canziani OF, Palutikof JP, van der Linden PJ, Hanson CE (eds) Climate change 2007: impacts, adaptation and vulnerability. Contribution of Working Group II to the Fourth Assessment Report of the Intergovernmental Panel on Climate Change. Cambridge University Press, Cambridge, pp 7-22

Jerneck A, Olsson L, Ness B, Anderberg S, Baier M, Clark E, Hickler T, Hornborg A, Kronsell A, Lövbrand E, Persson J (2011) Structuring sustainability science. Sustain Sci 6:69-82

Kates R, Clark WC, Correll R, Hall JM, Jaeger CC, Lowe I, McCarthy JJ, Schellnhuber H-J, Bolin B, Dickson NM, Faucheux S, Gallopin GC, Gruebler A, Huntley B, Jager J, Jodha NS, Kasperson RE, Mabogunje A, Matson P, Mooney H, Moore B III, O'Riordan T, Svedin U (2000) Sustainability science. JF Kennedy School of Government, Harvard University, Cambridge. KSG Working Paper 00-018. http://ssrn.com/abstract=257359

Mimura N, Nurse L, McLean R, Agard J, Briguglio L, Lefale P, Payet R, Sem G and 7 contributing authors (2007) Small islands. In: Parry ML, Canziani OF, Palutikof JP, van der Linden PJ, Hanson CE (eds) Climate change 2007: impacts, adaptation and vulnerability. Contribution of Working Group II to the Fourth Assessment Report of the Intergovernmental Panel on Climate Change, Cambridge University Press, Cambridge, pp 687-716

Pelling M, Uitto JI (2001) Small island developing states: natural disaster vulnerability and global change. Environ Hazards 3:49-62

Turner BL II (2010) Vulnerability and resilience; coalescing or paralleling approaches for sustainability science? Global Environ Change 20:570-576 